With 2 plates

Printed in Great Britain

\title{
Morphological Variants of Proteus hauseri
}

\author{
By J. N. COETZEE AND T. G. SACKS \\ Department of Microbiology, University of Pretoria, Pretoria, South Africa
}

(Received 9 February 1960)

\begin{abstract}
SUMMARY
Cultures of Proteus hauseri may consist of one or more of five colonial variants. Population pressure experiments started with one variant eventually yielded all other variants. $\mathrm{Y}$ variants form raised non-swarming colonies on a MacConkey-type agar at $37^{\circ}$, but swarm in concentric step-like rings at room temperature on this medium; they swarm in step-like concentric rings on nutrient agar at room temperature and at $37^{\circ}$. This variant is stable under conditions of logarithmic growth and is regarded as the wild type. Variant $\mathbf{X}$ is a typical Rough form and does not swarm under any circumstances. In continuous culture it mutates to the $\mathrm{Y}$ type at a high rate. The $W$ variant forms colonies very similar to those of the $Y$ variant, but like the $\mathrm{X}$ variant does not swarm. It is stable under conditions of continuous culture, but mutates on MacConkey agar to $\mathrm{X}$ and $\mathrm{Y}$ variants at low rates. On MacConkey agar at $37^{\circ}$ the $\mathrm{Z}$ type appears as a flat amorphous colony surrounded by a continuous thin film of swarm. It also swarms at room temperature. This variant is replaced by a mixture of $\mathrm{Y}$ and $\mathrm{W}$ colonial forms in continuous culture experiments. Drop-like colonies, the 'Tröpfchenform' previously described by Weil \& Felix (1917) were also encountered. Drop-like colonies are unpredictable in appearance and were not studied in detail.

Hanging-drop preparations of $4 \mathrm{hr}$. old broth cultures at $37^{\circ}$ of either $\mathrm{W}$ or $\mathbf{X}$ colonial variants (which never swarm) reveal many motile forms. Young broth cultures of the other three variants consist of forms which are all actively motile. Lytic phage for a particular strain is active on all its variants except the $\mathbf{X}$ or Rough type which is also the only variant to form unstable suspension in saline and in broth. The $\mathrm{Y}, \mathrm{W}$ and $\mathrm{Z}$ variants described here correspond reasonably well to the A, B and C phases of Belyavin (1951). The H, O terminology of Weil \& Felix (1917) is not suitable and the nomenclature of Belyavin (1951) may be more satisfactory.
\end{abstract}

\section{INTRODUCTION}

Weil \& Felix (1917) were the first to describe variants of the usual swarming type of Proteus. They designated the latter as $\mathbf{H}$ (Hauch) and the non-swarming slimy colonies as $\mathbf{O}$ (ohne Hauch). They also mentioned 'Tröpfchenform' or drop-like colonies. Other workers have described colonies of Proteus 'resembling those of B. coli' (Wenner \& Rettger, 1919; Yacob, 1932) and Felix (1923), Moltke (1928) and Felix \& Rhodes (1931) described what appear to be Rough colonial forms. Perch (quoted by Kauffmann, 1951) differentiated two types of colony on $0 \cdot 1 \%$ phenol agar: a 'dull' one which was flat and surrounded by a narrow swarming zone and 
a 'bright' one which was domed and sharply defined. Belyavin (1951) was the first to study morphological variants of the group systematically. Three colonial forms were described, which he provisionally labelled $\mathrm{A}, \mathrm{B}$ and $\mathrm{C}$ phases. On nutrient agar overnight at $37^{\circ}$ the $\mathrm{A}$ phase swarmed in a characteristic step-like concentric ring pattern. The $B$ phase usually did not swarm while the $C$ phase swarmed in a uniform film without step formation. Coetzee (1959 $a$ ) described properties of a Rough form of a vulgaris variety of Proteus hauseri and mentioned other variants encountered. These were non-committally labelled with letters from the lower end of the alphabet. The present object is to characterize these variants and correlate the findings with those of Belyavin.

\section{METHODS}

The strains used were described by Coetzee (1958), and consisted of ten vulgaris and twelve mirabilis varieties of Proteus hauseri. The cultures were isolated during 1956 and have been maintained on nutrient agar slopes at $4^{\circ}$. The broth used consisted of $2 \%(\mathrm{w} / \mathrm{v})$ 'Lab-lemco', $4 \%(\mathrm{w} / \mathrm{v})$ Difco peptone and $0.5 \%(\mathrm{w} / \mathrm{v})$ sodium chloride at $\mathrm{pH} \mathbf{7 \cdot 4}$. The plating medium was a MacConkey-type agar made up as follows: Peptone (Oxoid) 40 g., bile salts (Oxoid) 3 g., sodium chloride 10 g., agar (B.B.L.) 34 g., distilled water $2000 \mathrm{ml}$. Dissolved in steamer and 20 g. of bacteriological lactose (Gurr), 6.0 ml. of $1 \%(\mathrm{w} / \mathrm{v})$ neutral red, and $2.0 \mathrm{ml}$. of $0.1 \%(\mathrm{w} / \mathrm{v})$ crystal violet added. $\mathrm{pH}$ adjusted to $7 \cdot 2$, and autoclaved at $15 \mathrm{lb}$. for $15 \mathrm{~min}$. The method of initiation of cultures from single cells has been described (Coetzee, 1959 $a$ ) and consisted of starting at least treble the number of cultures required with equal small inocula of $6 \mathrm{hr}$. broth cultures. If more than one-third of these cultures remain sterile it follows from the Poisson distribution that the remainder were initiated with an average of one viable organism. Continuous culture experiments consisted of maintaining logarithmic growth in cultures originally initiated with single organisms by subculturing $c .10^{4}$ organisms at $8 \mathrm{hr}$. intervals into $800 \mathrm{ml}$. of fresh pre-warmed broth. All cultures were continually aerated and agitated by a stream of sterile air, and incubated at $37^{\circ}$. This method has also been described $($ Coetzee, 1959a). Population pressure experiments were done by starting a single organism culture in $40 \mathrm{ml}$. of broth. After $24 \mathrm{hr}$. incubation at $37^{\circ}, 1 \mathrm{ml}$. of this culture (titre $c .4 \times 10^{8} / \mathrm{ml}$.) was transferred to $40 \mathrm{ml}$. of fresh broth. This procedure allowed only 5-6 generations of growth before the $M$ concentration was again reached. Further similar subcultures were done, and at intervals suitable dilutions were plated to determine the colonial morphology of the organisms present. The estimation of mutation rates by counting mutant outgrowths from parent colonies was as described for other systems (Ryan, Schwartz \& Fried, 1955; Coetzee, $1959 b, c$; Coetzee \& Sacks, 1960). Colonial morphology was studied by plating suitable dilutions of broth cultures on MacConkey-type agar plates (see Coetzee, 1959a). The saline stability of the organisms was tested by the method of Pandit \& Wilson (1932) with concentrations of $\mathrm{NaCl}$ ranging from $0 \cdot 4$ to $5 \%$. 


\section{RESULTS \\ Morphological variants}

All the strains examined were found to consist of one or more of five colonial variants. The variants showed no predilection for mirabilis or vulgaris strains.

$Y$ variants. After $16 \mathrm{hr}$. incubation on MacConkey-type agar at $37^{\circ}$ these colonies are 3-4 $\mathrm{mm}$. in diameter, dome-shaped, circular in outline with an entire or slightly striated edge and possess a beaten copper surface. There is usually no swarming at $37^{\circ}$ on this medium although sometimes, especially after longer periods of incubation, the edge may be less well defined and merges with $c .1 \mathrm{~mm}$. of swarming spread. After $2 \mathrm{hr}$. at room temperature (18-24 $4^{\circ}$ ) these colonies are surrounded by a halo of diffuse spread $c .2 \mathrm{~cm}$. in diameter (Pl. 1, fig. 1). Swarming appears earliest between crowded colonies. After $24 \mathrm{hr}$. at room temperature the colony assumes the wellknown step-like concentric ring appearance associated with Proteus (Pl. 1, fig. 2). Rauss (1936) demonstrated a very similar temperature effect on the swarming tendency of Proteus morgani. MacConkey plates inoculated with $\mathrm{Y}$ variants and kept at room temperature overnight show step-like concentric ring swarming. Swarming on blood agar or nutrient agar plates kept at $37^{\circ}$ or room temperature for $16 \mathrm{hr}$. is always concentric and step-like. Increased concentrations of agar tend to diminish the diameter of the rings of swarming and diminishing the concentration has the reverse effect; below $1 \%$ swarming is continuous.

$Z$ variants. After $16 \mathrm{hr}$. incubation on MacConkey-type agar at $37^{\circ}$ these colonies differ markedly from the $\mathrm{Y}$ type. They are usually larger and flatter and possess a finely granular surface. The outline is irregular and the edge merges with a thin film of swarming at least $2 \mathrm{~cm}$. in diameter. If the colonies are now kept at room temperature they become amorphous and the uniform film of swarming spreads showing very little, if any, of the concentric step-like appearance of $\mathrm{Y}$ variants (Pl. 1, fig. 3). Swarming is more pronounced on blood agar and nutrient agar than on MacConkey agar. Concentrations of agar above $2 \%$ diminish the swarming and make the latter more $\mathrm{Y}$-like. Swarming of both $\mathrm{Y}$ and $\mathrm{Z}$ variants is usually more extensive at room temperature than at $37^{\circ}$. $\mathrm{Y}$ and $\mathrm{Z}$ variants of the same strain swarm into one another without a line of demarcation.

$X$ variants. These are similar to the Rough colonial form of strain $\mathbf{1 5}$ previously described (Coetzee, $1959 \mathrm{a}$ ). After $16 \mathrm{hr}$. incubation at $37^{\circ}$ on MacConkey-type agar they are larger and flatter than a $\mathbf{Y}$ variant of the same strain. The outline is irregular and the edge is concave and bevelled. The surface is rough ( $\mathrm{Pl}$. 1, fig. 4). These colonies do not swarm under any circumstances.

$W$ variants. These variants were referred to previously (Coetzee, 1959 a) but not described. After $16 \mathrm{hr}$. on MacConkey-type agar at $37^{\circ}$ they are smooth, shiny, with a circular outline, more heaped and slightly smaller than the corresponding $\mathrm{Y}$ colony (Pl. 1, fig. 5). They have a well-defined edge and like the $\mathrm{X}$ variety do not spread with any combination of temperature and medium tested. It is not always easy to distinguish overnight growths at $37^{\circ}$ of $\mathrm{Y}$ and $\mathrm{W}$ colonies on MacConkey agar. The best way of doing this is to leave the plates at room temperature for a few hours when $Y$ colonies develop their characteristic halo of spread (Pl. 1, fig. 1). After 2-5 days many $W$ colonies on MacConkey agar at room temperature develop a variable number of outgrowths from their surfaces (Pl. 2, fig. 6). The outgrowths 
are of two kinds; one type resembles the step-like spread of a $\mathrm{Y}$ variant while the other has the rough surface associated with $\mathbf{X}$ variants. Subcultures of the former yield $\mathrm{Y}$ colonies and those of the latter, $\mathrm{X}$ colonies (see later).

Drop-like variants. After $16 \mathrm{hr}$. incubation on MacConkey-type agar at $37^{\circ}$ these variants consist of a $\mathrm{Y}$-like mother colony surrounded by numbers of small colonies (Pl. 2, fig. 7). Between constituent colonies of each galaxy there is usually a thin film of spread detectable. This assumes the typical $\mathbf{Y}$ swarming pattern after a further $18 \mathrm{hr}$. at room temperature (Pl. 2, fig. 8). These drop-like colonies only appear at $37^{\circ}$. Duplicate plates inoculated and left at room temperature show Y-like swarming without any droplet formation. The colonies do not breed true and usually become $\mathrm{Y}$ variants on subculture. As a result of their unpredictable and transient appearances they have not been extensively studied. These variants resemble the 'Tröpfchenform' colonies mentioned by Weil \& Felix (1917). The small colony variants, hardly noticeable after $24 \mathrm{hr}$. growth, described by Felix (1923), were not encountered. No biochemical differences have been detected between morphological variants of any one strain.

Lytic phage isolated for each of the thirty-one strains (Coetzee, 1958) was active on all constituent variants of a strain, apart from the $X$ variants which were always phage resistant. With the exception of $\mathbf{X}$ forms, colonies from all variants on nutrient agar formed stable suspensions in saline and in broth. The $\mathbf{X}$ form rapidly deposits at the bottom of the tube leaving the supernatent fluid clear.

Hanging-drop preparations of $4 \mathrm{hr}$. broth cultures at $37^{\circ}$ reveal $\mathrm{Y}$ and drop-like variants as actively motile rods; the $\mathbf{Z}$ type consists mainly of motile filaments. The $\mathrm{W}$ form consists of cocco-bacillary and bacillary forms, c. $80 \%$ of which are motile. X-types under similar conditions consist of bacillary forms only, $c .40 \%$ of which are motile. After further periods of incubation the motility of all variants decreases both quantitatively and qualitatively. It has however been established that the $\mathbf{W}$ and $\mathbf{X}$ colonial variants, which do not swarm, certainly show many motile forms in young broth cultures.

To examine whether the five colonial variants described are peculiar to old stored cultures, a number of freshly isolated strains of Proteus hauseri were studied. These invariably consisted of one or more of the above-mentioned variants.

\section{Interrelationships}

Population pressure experiments. In these experiments, cultures initiated with a single organism of a particular morphological variant, in due course produced the whole gamut of morphological types. The variants did not appear in any set sequence or combination and it was impossible to determine the detailed lineage of a particular morphological variant from these qualitative experiments. $\mathbf{Y}$ and $\mathbf{W}$ colonial variants usually predominated in the complex conditions prevailing in the ageing and starving populations.

Continuous culture experiments. Quantitative results are only available for strain 15 (vulgaris) but have been qualitatively confirmed for mirabilis strains 34 and 13. Coetzee (1959 $a$ ) described how a culture initiated from a single X-variant organism of strain 15 and maintained in logarithmic growth was gradually replaced by $\mathrm{Y}$ colonial variants; the process was complete after $350 \mathrm{hr}$. Experiments maintained for a further $\mathbf{5 0 0} \mathrm{hr}$. showed the $\mathrm{Y}$ type to be stable under the prevailing conditions. 
The random occurrence of $\mathrm{Y}$ from $\mathrm{X}$ variants was established by means of fluctuation tests (Coetzee, 1959a), and the mutation rate involved was determined by means of continuous cultures. This proved to be $5 \cdot 3 \times 10^{-3} /$ bacterium/generation. Continuous cultures started with single $W$ variant organisms were also perfectly stable in experiments lasting for $300 \mathrm{hr}$. Similar experiments conducted with a $\mathrm{Z}$ colonial type resulted in its gradual replacement by a mixture of $\mathrm{Y}$ and $\mathrm{W}$ variants. The process was complete within a period ranging from 300 to $500 \mathrm{hr}$. for different $\mathrm{Z}$ strains. In different experiments (even with the same $\mathbf{Z}$ strain) the sequence with which the $\mathrm{Y}$ and $\mathrm{W}$ variants was detected varied and one variant might precede the other by as much as $48 \mathrm{hr}$. Frequently they were detected simultaneously. It would appear as if, under the particular conditions prevailing in continuous culture experiments, $\mathrm{Z}$ variants can independently give rise to $\mathrm{Y}$ and $\mathrm{W}$ colonial forms. $A$ test to prove the mutational origin of these variants from the $Z$ type has not been devised. The ratio of $\mathrm{Y}$ to $\mathrm{W}$ variants varied in different experiments but was maintained at a constant value for as long as has been investigated (200 hr.). This

Table 1. Results of an experiment to determine the mutational origin and mutation rates of $X$ and $\boldsymbol{Y}$ variants from $W$ variants of Proteus strain 15

No outgrowths

1 outgrowth

2 outgrowths

3 outgrowths

4 outgrowths

Mean no. outgrowths/colony $(m)$

Probability of drawing a similar sample of outgrowths from a Poisson distribution with $m$ as mean $(P)$

Mutation rate/bacterium/generation $(m \ln 2 / N)$

\begin{tabular}{rr}
\multicolumn{2}{c}{ Variant colonies (no.) } \\
\hline$X$ & \multicolumn{1}{c}{$Y$} \\
1759 & 1569 \\
440 & 569 \\
72 & 124 \\
5 & 14 \\
2 & 2 \\
0.226 & 0.381 \\
0.22 & $0 \cdot 34$
\end{tabular}

$2 \times 10^{-11} \quad 2.9 \times 10^{-11}$

$N=$ mean total bacterial count of five 5 -day $W$ colonies showing no outgrowths $=9 \cdot 2 \times 10^{9}$.

finding was confirmed for strain 15 by doing reconstruction experiments. Continuous culture experiments were started with a known ratio of the two variants. The initial ratio was maintained for long periods of time.

Outgrowths of $W$ colonies. Counts of the number of $\mathbf{Y}$ and $\mathbf{X}$ outgrowths from $\mathrm{W}$ colonies of strain 15 after 5 days at room temperature are presented in Table 1. After 5 days at room temperature no more outgrowths appeared. One hundred and ten $W$ colonies which showed no outgrowths at this stage were cut out and each entire colony spread on the surface of a separate MacConkey agar plate. After $16 \mathrm{hr}$. at $37^{\circ}$ and a further $8 \mathrm{hr}$. at room temperature plates were examined for swarming growth. Only three plates showed swarming. This implies that the mean number of undetected $\mathrm{Y}$ outgrowths per colony is negligible. A simple test for concealed $\mathrm{Z}$ growths was not devised. The $\boldsymbol{P}$ values given in Table 1 represent the chance of drawing a similar sample from a Poisson distribution with a mean equal to the observed mean number of outgrowths per colony. The values obtained are taken to indicate that the outgrowths were randomly distributed and support the theory of the mutational origin of events which started the clonal outgrowths (Ryan et al. 1955). Mutation rates are also presented in Table 1 ; these are low and may be over- 
estimated because acid-Giesma staining (Bisset, 1950) of $W$ organisms reveals 1-4 chromatinic bodies per organism. These low mutation rates are compatible with the fact that under conditions prevailing in continuous culture, $\mathbf{W}$ organisms are stable.

\section{DISCUSSION}

The microscopic pleomorphism which induced Hauser (1885) to name these organisms after the Homeric sea deity Proteus is reflected in variations of colonial morphology. It becomes a matter of some interest to determine which is the wild type. It has been established that on solid media $\mathrm{Y}$ and $\mathrm{X}$ variants arise from the $\mathbf{W}$ form. The mutational origin of these two variants from the $\mathbf{W}$ form has been established for strain $\mathbf{1 5}$ and the mutation rate determined. The mutation rate of the $\mathrm{X}$ to $\mathrm{Y}$ form has also been determined for strain 15 (Coetzee, 1959a). In continuous cultures the $Z$ form is replaced by a mixture of $Y$ and $W$ variants. The latter combination is also most prevalent in population pressure experiments. Many of these experiments have been conducted with variants of only one strain, but there is no reason to doubt the general applicability of results obtained. These results suggest that the $\mathrm{Y}$ variant is the modal type. The frequency with which this variant is isolated from clinical material supports this suggestion. The $\mathbf{H}$ form of Weil \& Felix (1917) corresponds either to our $\mathrm{Y}$ or $\mathrm{Z}$ variants. The descriptions of their $O$ form and of the coliform-like colonies of Wenner \& Rettger (1919) and Yacob (1932) may refer to our $W$ variant, but it is difficult to relate the variants described by Perch (Kauffmann, 1951) to the present varieties.

Belyavin (1951) did not mention the effect of temperature on the swarming phenomenon of his A phase on MacConkey agar, yet the characteristics of A phase swarming on nutrient agar appear to be identical with those of the $\mathbf{Y}$ variants described here. Other features agree and Belyavin's phase A must be considered very similar to our $\mathbf{Y}$ variants. Belyavin regarded this phase $\mathbf{A}$ as the modal form. The W variants described here resemble Belyavin's B phase. Differences are that some of his young cultures spread on nutrient agar and some were unstable in saline. He regarded the $B$ phase as showing some Rough characteristics. We have not been able to confirm this since our $W$ variants are stable in saline and broth, and are susceptible to phage active on the corresponding wild type. We have not, however, done any serological tests. Belyavin's C phase did not swarm on MacConkey agar. This may have been due to differences in ingredients of media used. Some of his C-phase colonies were unstable in saline. However, the type of swarming on nutrient agar was like that of our $\mathrm{Z}$ variants. The microscopic morphology was also identical and the $\mathbf{C}$ phase and the $\mathbf{Z}$ variants can be regarded as similar. If the foregoing is accepted then we have demonstrated, by means of continuous cultures, a direct transition from the $\mathbf{C}$ to the $\mathbf{B}$ phase, a change which Belyavin did not report.

Despite Krikler's (1953) demonstration of the unreliability of employing the $\mathrm{C}(\mathrm{Z})$ phase, the fact that $\mathrm{A}(\mathrm{Y})$ and $\mathrm{C}(\mathrm{Z})$ variants of a particular strain swarm into one another without a line of demarcation may be taken as support (Dienes, 1946) of Belyavin's finding of antigenic similarity between his $\mathbf{A}$ and $\mathbf{C}$ phases.

On the question of nomenclature, the $\mathrm{O}$ and $\mathrm{H}$ terminology of Weil \& Felix (1917) deserves precedence. By common usage the $\mathrm{OH} \rightarrow \mathrm{O}$ variation implies loss of flagellar antigens. Reference to our W or to Belyavin's B forms, which show many 
motile organisms, as $\mathbf{O}$ forms would therefore be misleading. Weil \& Felix did not distinguish between the two varieties of swarmers described here and their $\mathbf{H}$ term is thus ambiguous. The $\mathbf{X}$ colonial type is almost certainly an $\mathbf{R}$ variant in the terminology of Arkwright $(1920,1921)$ and, although no serological studies have been done, the latter symbol should be applied. Close identity has been demonstrated between our Y, W and Z variants and Belyavin's A, B and C phases, respectively. While many of Belyavin's strains had been maintained in stock culture for over 10 years, our cultures were less than 3 years old when examined and have never been dried. Moreover, newly isolated strains showed the same phenomena. It is possible that differences encountered may be explained on the basis of age of cultures examined; if this should prove to be so then it is recommended that Belyavin's terminology be adopted.

Acknowledgement is made to Mrs M. Riley and Mr K. van Vliet for technical assistance rendered. The senior author is in receipt of a grant from the South African Council for Scientific and Industrial Research.

\section{REFERENCES}

Arkwright, J. A. (1920). Variation in bacteria in relation to agglutination by salts and by specific sera. J. Path. Bact. 23, 358.

Arkwright, J. A. (1921). Variation in bacteria in relation to agglutination both by salts and by specific serum. J. Path. Bact. 24, 36.

Belyavin, G. (1951). Cultural and serological phases of Proteus vulgaris. J. gen. Microbiol. $5,197$.

Bisset, K. A. (1950). The Cytology and Life-History of Bacteria, 1st ed. Edinburgh: E. and S. Livingstone.

Coetzee, J. N. (1958). The characterization of a series of Proteus bacteriophages. S. Afr. J. lab. clin. Med. 4, 147.

Coetzee, J. N. (1959a). Some properties of a morphological variant of a strain of Proteus vulgaris. S. Afr. J. lab. clin. Med. 5, 16.

CoEtzeE, J. N. (1959b). A comparison of various methods of estimating mutation rates for the system Phase-I to Phase-II Shigella sonnei. S. Afr. J. lab. clin. Med. 5, 103.

Coetzee, J. N. $(1959 c)$. The late lactose-fermenting property of Shigella sonnei. S. Afr. J. lab. clin. Med. 5 , 170.

Coetzee, J. N. \& SAcks, T. G. (1960). The late sucrose-fermenting property of Proteus mirabilis. S. Afr. J. lab. clin. Med. 6, 49.

Dienes, L. (1946). Reproductive processes in Proteus cultures. Proc. Soc. Exp. Biol., N.Y. 63, 265.

Felix, A. (1923). Über Varianten der Proteus X Stämme. Z. ImmunForsch. 35, 57.

Fenix, A. \& Rhodes, M. (1931). Serological varieties of typhus fever. J. Hyg., Camb. 31, 225.

HAUSER, G. (1885). Über Fäulnissbacterien. Leipzig: F. G. W. Vogel.

Kaufmann, F. (1951). Enterobacteriaceae, 1st ed. Copenhagen: Munksgaard.

Krikler, M. S. (1953). The Serology of Proteus vulgaris. Ph.D. Thesis: University of London.

MoLtKe, O. (1928). Investigation of morphological characteristics of Bac. proteus. Medd. Seruminst. Kbh. 18, 27.

Pandit, S. R. \& Wilson, G. S. (1932). The relation between specific and non-specific agglutination in the Brucella group. J. Hyg., Camb. 32, 45.

Rauss, K. (1936). The systematic position of Morgan's bacillus. J. Path. Bact. 42, 183.

Ryan, F. J., Schwartz, M. \& Fried, P. (1955). The direct enumeration of spontaneous and induced mutations in bacteria. J. Bact. 69, 552. 
Weir, E. \& Felix, A. (1917). Weitere Untersuchungen über das Wesen der Fleckfieberagglutination. Wien. klin. Wschr. 30, 1509.

Wenner, J. J. \& RetTger, L. F. (1919). A systematic study of the Proteus group of bacteria. J. Bact. 4, 331.

YACOB, M. (1932). Studies of genus Proteus. Indian J. med. Res. 19, 787.

\section{EXPLANATION OF PLATES}

Plate 1

Colonial morphology of Proteus hauseri variants on MacConkey-type agar. All figures life size.

Fig. 1. $\mathrm{Y}$ variants after $16 \mathrm{hr}$. incubation at $37^{\circ}$ followed by $2 \mathrm{hr}$. at room temperature.

Fig. 2. $\mathrm{Y}$ variants after $24 \mathrm{hr}$. at room temperature.

Fig. 3. $Z$ variants after $24 \mathrm{hr}$. at room temperature.

Fig. 4. Four $X$ variants and two $W$ variants, after $16 \mathrm{hr}$, at $37^{\circ}$.

Fig. 5. W variants after $16 \mathrm{hr}$. at $37^{\circ}$.

\section{Plate 2}

Colonial morphology of Proteus hauseri variants on MacConkey-type agar.

Fig. 6. W variants. 5-day colony showing Y-type (left) and X-type (right) outgrowths; magnification $c . \times 6$.

Fig. 7. Drop-like variants after $16 \mathrm{hr}$. at $37^{\circ}$; magnification $c . \times 1.5$.

Fig. 8. Drop-like variants after $16 \mathrm{hr}$. at $37^{\circ}$ followed by $18 \mathrm{hr}$. at room temperature. Life size. 
Journal of General Microbiology, Vol. 23, No. 2

Plate 1
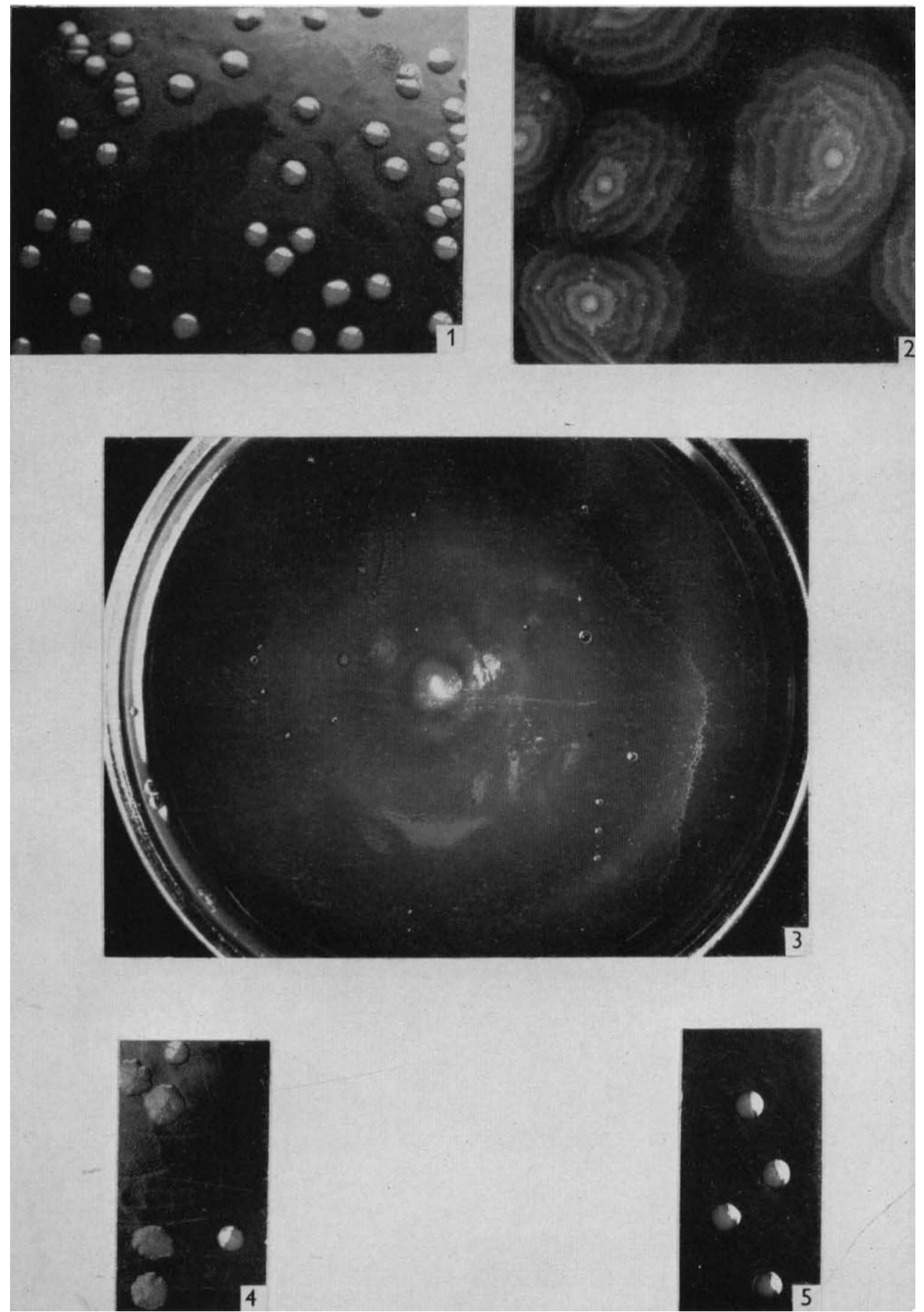

J. N. COE'TZEE AND 'T. G. SACKS

(Facing p. 216) 

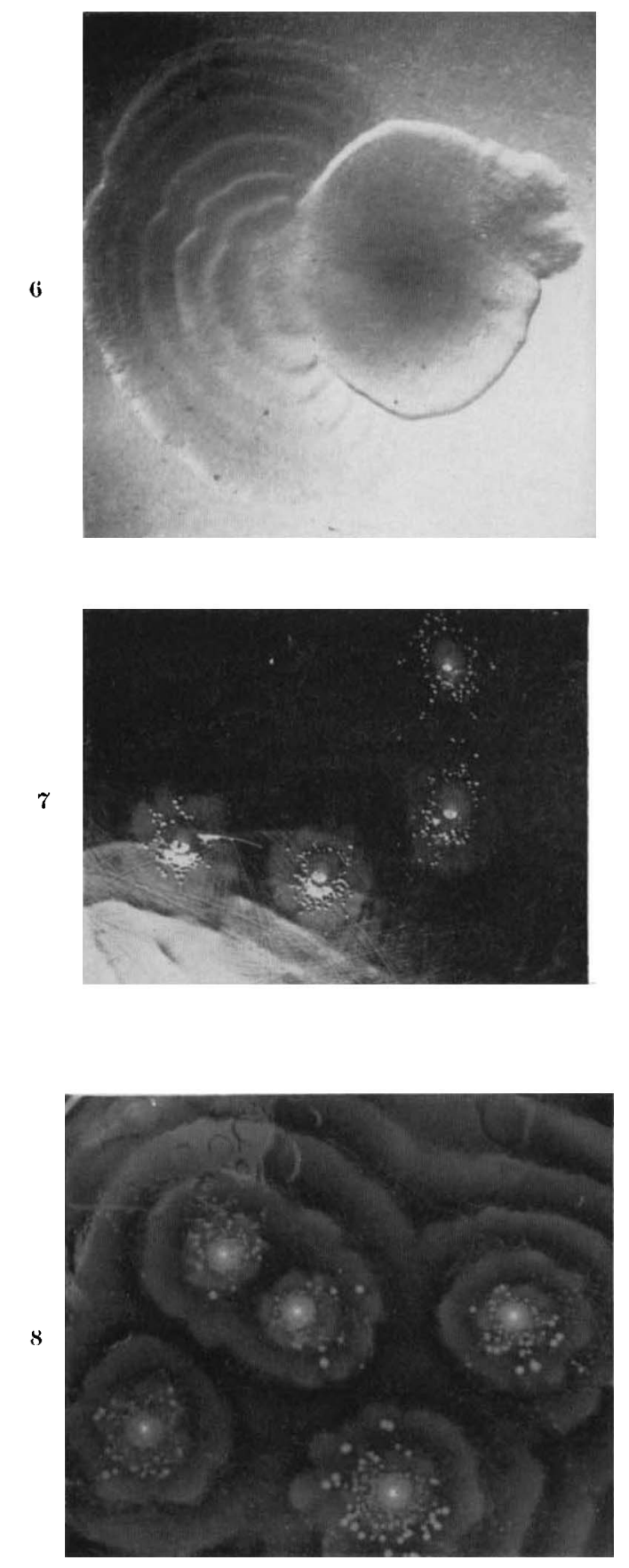

J. N. COETZEE AND T. G. SACKS 